\title{
DE QUE CRISE SE TRATA NA ADOLESCÊNCIA CONTEMPORÂNEA? ALGUMAS CONSIDERAÇÕES PSICANALÍTICAS E EDUCACIONAIS
}

\author{
JULIA M. B. ANACLETO ${ }^{1}$ \\ ORCID: https://orcid.org/0000-0002-2969-5286 \\ PAULA FONTANA FONSECA ${ }^{2}$ \\ ORCID: https://orcid.org/0000-0002-4887-3148
}

\begin{abstract}
RESUMO: Tributária da discursividade contemporânea, a adolescência pode ser entendida como efeito de uma produção política e social que demarca uma diferença com o infantil. Recorrendo ao arcabouço psicanalítico freudo-lacaniano, o presente artigo apresenta um debate teórico em torno do tema da crise da adolescência a partir da perspectiva dos estudos psicanalíticos no campo da educação. Para tanto, destaca a mudança de posição frente ao sexual como uma marca da transição pela qual passa o adolescente com consequências no laço social. Demonstramos que o caráter crítico da experiência adolescente não se restringe a alterações biológicas e individuais; antes, diz respeito a como essa experiência estruturante da constituição psíquica é significada pelo discurso social contemporâneo, levando muitas vezes a impasses e sofrimentos psíquicos. Deslocando a questão da adolescência de um âmbito individual e como simples consequência de uma fase da vida determinada por mudanças orgânicas, apontamos que a noção de crise desvela algo que diz respeito ao educar no mundo moderno e às consequências do tecnocientificismo como uma resposta que oblitera a responsabilidade dos adultos no endereçamento da palavra aos adolescentes, o que engendra uma nova forma de justificacionismo: o tecnocientificismo. Dentro deste cenário, interessa-nos destacar que a errância adolescente em busca de novas significações subjetivas pode encontrar no território escolar um espaço para ser experimentada sem que, apressadamente, seja capturada em um sentido fechado e frequentemente excludente. A ideia freudiana da impossibilidade própria ao ato de educar aponta para uma posição ética em face do desafio da modernidade no que diz ao que está em causa na experiência escolar.
\end{abstract}

Palavras-chave: psicanálise; adolescência; educação; crise

\section{OF WHAT CRISIS ARE WE TALKING ABOUT IN CONTEMPORARY ADOLESCENCE? SOME CONSIDERATIONS ON PSYCHOANALISYS AND EDUCATION}

\begin{abstract}
Tributary of contemporary discursivity, adolescence can be understood as the effect of a political and social production that demarcates a difference with childhood. Resorting to the FreudoLacanian psychoanalytic framework, this paper presents a theoretical debate around the theme of the crisis of adolescence from the perspective of psychoanalytic studies in the field of education. To do so,
\end{abstract}

\footnotetext{
${ }^{1}$ Universidade de São Paulo (USP). São Paulo, SP, Brasil. < julia.anacleto80@gmail.com>

${ }^{2}$ Universidade Ibirapuera (UNIB) e Universidade de São Paulo (USP). São Paulo, SP, Brasil. <pff@usp.br>
} 
it highlights the change of position in relation to the sexual as a mark of the transition through which the adolescent goes through, with consequences in the social bond. We demonstrate that the critical character of the adolescent experience is not restricted to biological and individual alterations; rather, it concerns how this structuring experience of the psychic constitution is signified by contemporary social discourse, often leading to impasses and psychic suffering. Displacing the question of adolescence from an individual scope and as a simple consequence of a phase of life determined by organic changes, we point out that the notion of crisis unveils something that concerns educating in the modern world and the consequences of techno-scientificism as a response that obliterates the responsibility of adults in addressing the word to adolescents, which engenders a new form of justificationism: techno-scientificism. Within this scenario, it interests us to highlight that the adolescent wandering in search of new subjective meanings can find in the school territory a space to be experienced without, hastily, being captured in a closed and often excluding sense. The Freudian idea of impossibility proper to the act of educating points to an ethical position in face of the challenge of modernity in what is at stake in the school experience.

Keywords: psychoanalysis; adolescence; education; crisis

\section{DE CUAL CRISIS SE TRATA EN LA ADOLESCENCIA CONTEMPORÁNEA? ALGUNAS CONSIDERACIONES PSICOANALÍTICAS Y EDUCACIONALES}

RESÚMEN: Heredera al discurso contemporáneo, la adolescencia puede entenderse como efecto de una producción política y social que establece una diferencia con la niñez. Utilizando el marco psicoanalítico freudo-lacaniano, este artículo presenta un debate teórico sobre el tema de la crisis adolescente desde la perspectiva de los estudios psicoanalíticos en el campo de la educación. Por lo tanto, destaca el cambio de posición en relación con lo sexual como una indicación de la transición que atraviesa el adolescente con consecuencias en el lazo social. Demostramos que el carácter crítico de la experiencia adolescente no está restringido a cambios biológicos e individuales; más bien, se refiere a cómo esta experiencia estructurante de la constitución psíquica está representada por el discurso social contemporáneo, que a menudo conduce a impases y sufrimientos psíquicos. Desplazando la cuestión de la adolescencia desde un contexto individual y como una simple consecuencia de una fase de la vida determinada por cambios orgánicos, señalamos que la noción de crisis desvela algo que concierne al educar en el mundo moderno y a las consecuencias del tecnocientíficismo como una respuesta que oblitera la responsabilidad de los adultos al dirigir la palabra a los adolescentes. Dentro de este escenario, destacamos que la errancia de los adolescentes en su búsqueda por nuevas significaciones subjetivas puede encontrar en el territorio escolar un espacio para ser experimentada sin ser capturada rápidamente en un sentido cerrado y, a menudo, excluyente. La idea freudiana de lo imposible, propia del acto de educar, señala una posición ética frente al desafío que implica la experiencia escolar.

Palabras clave: psicoanálisis; adolescencia; educación; crisis 


\section{INTRODUÇÃO}

A ideia de adolescência é tributária da discursividade contemporânea, ou seja, ela é efeito de uma produção política e social que demarca uma diferença com o infantil. Muito se fala sobre a adolescência como um tempo de crise, principalmente no que diz respeito às relações com os adultos, seja no ambiente familiar, escolar ou outros espaços institucionais. Mas será que essa tal crise da adolescência seria algo inerente a uma fase da vida? Quais as questões presentes na ideia de uma crise da adolescência? Como isso concerne especialmente à escola?

Procuraremos ao longo do presente artigo sustentar que, para além dos impasses subjetivos que em cada um possa vir a aparecer face ao desafio da adolescência, sua apreensão como sendo da ordem de uma crise diz respeito ao laço social. Recorrendo ao arcabouço psicanalítico freudo-lacaniano, é possível afirmar que a adolescência se apresenta como referida à mudança de posição frente ao sexual e, portanto, também de posição no discurso (Alberti, 2009). Isso implica que o caráter crítico dessa experiência não se restringe a alterações biológicas e individuais; antes, diz respeito a como essa experiência estruturante da constituição psíquica é significada pelo discurso social contemporâneo, levando muitas vezes a impasses e sofrimentos psíquicos.

Se, de um lado, a adolescência confronta o sujeito com o desvelamento do caráter enganoso da promessa infantil de completude, de outro, assistimos à recusa do discurso social em reconhecer o caráter ilusório de tal promessa (Alberti, 2009). Decorreria daí que a adolescência seja vista tanto como ideal social alimentado pela crença na junção entre uma suposta natureza infantil e um corpo de adulto, quanto como seu avesso, na figura do adolescente "problemático" como aquele que não corresponde ao ideal imaginário imposto (Pereira e Gurski, 2014).

As duas visões apenas aparentemente antagônicas que convivem no tempo atual respondem à tentativa de rechaço da falta estrutural como motor da subjetividade moderna que só por esse caminho pode estar marcada pela indeterminação. A própria modernidade se apresenta como tensionada entre a abertura do futuro à indeterminação graças ao declínio do poder da providência divina e a emergência de um novo determinismo dado pelo discurso tecnocientífico (Lefort, 1979/1999). A prevalência atual da lógica do rendimento, condizente com a condução do progresso técnico às suas últimas consequências, tem acirrado a crise que não diz respeito a um suposto "em si”" da adolescência, mas à tarefa de educar e sua necessária referência ao passado como baliza para a construção de um futuro aberto ao novo (Arendt, 1957/2005).

Por fim, traremos algumas considerações sobre a experiência escolar de jovens e o papel capital da escola na atualidade dentro deste cenário, pois ela participa do discurso social e participa da estigmatização e patologização do adolescente, assim como guarda um enorme potencial de exercer a função simbolizante (Duschatzky, 2008) necessária para que a adolescência seja a travessia que conduz o sujeito a um dizer próprio, elaboração de seu lugar no mundo e de sua inscrição em uma tradição. A sustentação de tal papel social da instituição escolar não depende fundamentalmente de teorias pedagógicas ou métodos de ensino. Está, antes, atrelada a um desafio ético para o qual os estudos da psicanálise na educação pretendem contribuir a seu modo.

\section{OS DOIS TEMPOS DA SEXUALIDADE}

Freud, em seus Três ensaios sobre a teoria da sexualidade (1905/1996), dedicou o terceiro estudo ao tema das transformações pubertárias. O texto, publicado originalmente em 1905, sofreu sucessivas revisões e adendos, o que permite qualificá-lo como uma "obra aberta", na qual "diferentes teses sobre a pulsão sexual - muitas vezes, contraditórias entre si - são apresentadas" (Amaral, 1995, p.64). Amaral realiza um trabalho detalhado de análise comparando a versão original com as sucessivas revisões e aponta haver uma ruptura entre os dois primeiros ensaios - que versam sobre as aberrações sexuais e a sexualidade infantil - e aquele que se dedica à puberdade. Segundo a autora, esse último está imbuído de um finalismo evolutivo que sucessivamente será incorporado à obra como um todo. O caráter perverso polimorfo da sexualidade, pregnante na obra de 1905, vai dando lugar a uma noção de organização bem 
definida, dividida em etapas - oral, anal e genital. Esse estudo não só ressalta a complexidade do pensamento freudiano como também algumas das suas contradições, o que possibilitou uma diversidade de leituras acerca do tema da adolescência no campo psicanalítico.

A escolha freudiana pelo termo puberdade chama a atenção. Estaria Freud privilegiando o aspecto orgânico maturacional em detrimento do anímico? Mateus (2008) destaca que o uso desse termo era mais comum nos meios em que Freud frequentava e realiza um exercício de exegese de modo a depreender qual seu sentido dentro do texto freudiano. Em sua leitura, destaca que a ênfase recai em a puberdade ser um segundo momento da sexualidade que vem desarranjar a conformação subjetiva construída até então.

Sob o termo puberdade, Freud (1905/1996) compreende tanto as transformações corporais como as psíquicas. Isso fica evidenciado quando discorre sobre os três estímulos que provocam a excitação sexual: o primeiro deles advém do mundo exterior por meio da excitação de zonas erógenas; o segundo do mundo interior, do organismo (seguindo vias até então pouco conhecidas); o terceiro é proveniente da vida anímica que, conforme define, "constitui um repositório de impressões externas e um receptor de excitações internas" (Freud, 1905/1996, p.150). É justamente esse terceiro caminho da excitação que permite afirmar que quando Freud falava de puberdade ele visava o psíquico (Alberti, 2009).

É importante destacar que para Freud a sexualidade humana, radicalmente distinta do que está em jogo no reino animal, possui dois tempos. A ideia de uma bitemporalidade na constituição da sexualidade coloca em xeque a visão evolutiva, pois é de fundamental importância essa força de ruptura que marca o que Freud chama de período de latência. A concepção freudiana de sexualidade infantil pressupõe um tipo de temporalidade que não é propriamente cronológica. Isso porque o infantil não é exatamente um período da vida, mas algo que ganha significação retroativamente. A infância é sempre perdida, e será a emergência desse segundo tempo da sexualidade que, a posteriori, significará o tempo anterior como infantil. O infantil é, portanto, o "antes" enquanto significado no "depois".

A proposição de uma sexualidade cindida em dois tempos é solidária à sustentação de que sua origem está ligada ao investimento narcísico dos pais nos filhos na tenra infância, subvertendo o organismo em um corpo libidinizado que busca tanto o prazer autoerótico quanto objetos de satisfação. Isso faz com que os pais sejam objetos privilegiados de investimento sexual nesse primeiro tempo. $\mathrm{O}$ período de latência é aquele que marca precisamente a ruptura dessa conformação sexual precoce através do recalque dos impulsos libidinais voltados aos genitores. Instala-se um período de relativa suspensão da sexualidade que será interrompido pela puberdade. Por isso ela pode ser pensada como irrupção do segundo tempo da sexualidade. Assim, a puberdade se apresenta como algo que compete ao corpo, mas que exige uma operação psíquica nova.

Conforme afirma Alberti (2009, p.167), "se a gestalt do corpo muda, o meio ambiente do adolescente também se modifica, pois a gestalt é justamente a imagem no espaço em que é percebida". A autora enfatiza, assim, a incidência que o laço social tem naquilo que é vivido como transformações da adolescência. Se há mudanças no corpo - e Freud destaca a menarca e a polução - há também mudanças na forma como esse corpo é percebido pelo outro.

A imagem que vigorava até então passa a ser insuficiente para fazer frente ao outro. Se a criança podia usufruir das teorias sexuais infantis - brincar de ser o papai ou a mamãe, acreditando que um dia, quando crescesse, ela viria a sê-lo -, para o adolescente elas não são mais anteparo diante da demanda do outro. Ele efetivamente cresceu.

Mateus (2008, p.230) destaca que:

mergulhado num caldo imaginário que não encontra suporte simbólico para sua tradução, a estranheza experimentada surge com o olhar que toma o corpo adolescente não propriamente como objeto de ternura ou de investimento narcísico, mas (do ponto de vista desse que olha) como objeto sexual.

Assim, a crise da adolescência aponta para uma insuficiência da imagem conformada até então frente ao Outro - e aqui fazemos referência à ideia de Outro proposto por Lacan não só como tesouro dos significantes, também como sendo a própria ordem simbólica e cultural. Se a criança, diante da pergunta "o que o Outro quer de mim?" - embutida nos famosos porquês que tentam saber o 
propósito de tudo -, formulou teorias de que um dia poderia ser como o papai ou a mamãe, para o adolescente esse futuro já chegou e o modo como o adulto olha esse jovem corpo denuncia que ele não mais é tomado apenas como objeto de investimento libidinal e narcísico, ele agora também é visto como objeto sexual.

O encontro desencontrado com a diferença sexual - lembremos que Freud foi enfático ao colocar dentre as teorias sexuais infantis aquela que dotava todos os seres de pênis e, mesmo diante de sua ausência, persistia a crença de que um dia iria crescer - coloca sob suspeita o que era tido como certo. Em outras palavras, as mudanças vividas na adolescência deflagram que as construções psíquicas que constituíam uma imagem com a qual a criança se identificava dão mostras de suas limitações. Esse abalo na imagem especular foi significado na contemporaneidade como sendo da ordem de uma crise.

Nesse sentido, poderíamos concluir que a crise é sim inerente à adolescência, enquanto momento de passagem para a vida sexual adulta. Contudo, convém perguntarmos se o caráter crítico da adolescência está todo encerrado na ideia de perda de uma suposta estabilidade anterior dada por uma imagem corporal coesa. Será que, numa caracterização psicanalítica da adolescência, devemos nos contentar com a explicação de que se trata da perda de uma plenitude vivida na infância? Ainda, quais as consequências que essas visões sobre o que está em jogo na adolescência têm sobre a educação dispensada aos adolescentes? Se sustentarmos, a partir de Freud, que a infância perdida só se constitui como tal a posteriori, tal ideia nos incita a ir além dessa caracterização da crise na adolescência.

Para tentar responder a essa questão, é importante retroceder ao primeiro tempo da sexualidade, aquele em que a criança busca sua satisfação no autoerotismo, mas também em se fazer objeto capaz de satisfazer o desejo parental e ser merecedora do investimento narcísico dedicado a ela. Em sua leitura estrutural do caso freudiano do pequeno Hans, Lacan (1956-7/1995) aborda o que seria o impasse próprio à constituição do sujeito dividido, impasse esse manifesto na angústia infantil. Com isso, coloca em questão a ideia de que a relação mãe-filho seria marcada pela satisfação plena que viria a ser perturbada pela incidência da figura castradora do pai. A leitura lacaniana desvela uma situação bem mais complexa, na qual a tensão própria ao advento do sujeito do desejo já está em causa na relação entre a mãe e a criança, dado que o objeto do desejo é um objeto perdido desde sempre.

A tentativa da criança, manifestada nas teorias sexuais infantis, de apreender um saber sobre o sexual que lhe possibilitasse ser o objeto do desejo materno, encontra o limite de um impasse na forma da irrupção da angústia, convocando a castração como passagem do impasse à impossível apreensão do objeto do desejo. A criança se depara, pois, com uma interdição, uma impossibilidade de saber e de dar consistência àquilo que é desejo de um desejo e não de objeto.

O pai assume a forma de uma função de metaforização, isto é, de substituição do objeto do desejo materno por um significante cuja significação é sempre instável. Em seu texto Subversão do sujeito e a dialética do desejo, Lacan (1960/1998, p.839) aponta que a verdadeira função do pai está em "unir (e não opor) um desejo à lei". Isso porque o que se transmite, via lei, é o desejo enquanto insatisfeito. Nas palavras de Safouan (1970, p. 85), trata-se do "desejo pela mãe imposto pelo pai, que o proíbe".

Essa interdição leva ao recalque das investigações sexuais infantis, dando ao período de latência essa característica de suspensão. Segundo Lacan, a operação da metáfora paterna é aquela da "instituição de alguma coisa que é da ordem do significante, que fica guardada de reserva, e cuja significação se desenvolverá mais tarde" (Lacan, 1957-8/1999, p. 202). Assim, a interdição que opera como um corte nas tendências libidinais infantis viria acompanhada de uma promessa futura de satisfação. A criança encontraria consolo nessa espera em que, inclusive, Freud (1905/1996) localiza a construção de processos sublimatórios nos quais a energia sexual é investida em objetos da cultura.

Segundo Rassial (1999), a criança aceitou a interdição porque esta foi acompanhada de uma promessa: a de um gozo anunciado para mais tarde. Contudo, a adolescência seria o momento em que "a promessa do Édipo se mostra enganadora" (Rassial, 1999, p. 47). O fato de que essa promessa seja enganosa diz respeito exatamente à ideia de que aquilo que a metáfora paterna institui, segundo os dizeres de Lacan, seja "da ordem do significante". O funcionamento da cadeia significante, ao qual todo ser falante está sujeito, se dá de um modo paradoxal. Por um lado, tende ao fechamento em uma significação última, ou seja, em um objeto capaz de satisfazer o desejo; ao mesmo tempo, possui uma força de abertura dada pelo fato de que o significante que completaria a cadeia e fecharia a significação é um significante da falta. 
É precisamente isso que Lacan (1956-7/1995) formula em torno do caso do pequeno Hans, afirmando que o sofrimento psíquico do garoto é expressão de um impasse em torno do jogo vivido nas relações parentais. Ao mesmo tempo em que sente que sua existência depende de sua posição de objeto do desejo materno, essa posição o coloca diante da ameaça de ser devorado por um desejo que é estruturalmente insaciável. A única saída possível desse impasse, segundo Lacan, é a incidência da ordem simbólica, isto é, da ordem do significante que permite que a significação do desejo materno seja deslizante, tornando a busca por esse objeto capaz de encerrar o sentido do desejo algo incessante. É isso o que está em jogo na incidência da metáfora paterna (Anacleto, 2019).

Com isso, nos deparamos com o fato de que a entrada no simbólico é aquela que instala o paradoxo entre fechamento e abertura da significação enquanto modo sempre conflituoso do sujeito dividido habitar a linguagem. É na chave da inscrição desse paradoxo que se pode compreender que ela se dê marcada por uma promessa de completude (fechamento) feita para não ser cumprida (abertura). $\mathrm{O}$ empenho em desvendar o mistério acerca de um suposto objeto do desejo materno introduz a criança no circuito desejante ao mesmo tempo em que esse circuito se retroalimenta da impossibilidade de que esse objeto seja apreensível.

Essa formulação lacaniana é aquela que lhe possibilita pensar uma estrutura de determinação da existência que não anule a possibilidade de emergência do sujeito como um efeito de diferença e, portanto, de indeterminação, visto que a representação do sujeito na linguagem estará sempre marcada por um resto que escapa à significação e que lhe possibilita inventar novas formas de (se) dizer. Portanto, a promessa de um gozo outro que não o parcial, promessa de completude numa significação última ou de um saber sobre o desejo, só pode ser enganosa.

É justamente na adolescência que, segundo Rassial, o sujeito se confronta pela primeira vez, com "a constatação de que qualquer promessa de um gozo outro promete somente a morte" (Rassial, 1999, p.47). Assim, para Rassial, a adolescência, enquanto conceito psicanalítico, deveria ser pensada como uma operação simbólica de confirmação (ou não) daquilo que se passou no primeiro tempo da sexualidade infantil enquanto inscrição do significante da falta.

\section{O DESPERTAR ADOLESCENTE E A CRISE DO EDUCAR}

Seguindo a esteira freudo-lacaniana, pode-se pensar em crise da adolescência no sentido de uma mudança estrutural que o jovem passa uma vez defrontado com o sexual e com a reafirmação desse abalo narcísico próprio à inscrição da metáfora paterna. No entanto, isso não significa que todo adolescente está em crise. Essa é uma diferenciação importante uma vez que nossa cultura vem atribuindo esse sentido ao que frequentemente ganha o nome de "aborrescência". Aqui entra em questão o modo como o discurso social dá sentidos a essa experiência constitutiva da subjetividade.

$\mathrm{Na}$ adolescência há uma mudança de posição estrutural em relação ao sexo que tem efeito no laço social. A experiência psicanalítica nos mostra que apenas ao escutar um sujeito podemos acompanhar os meandros de suas significações. Assim, essa vivência - na qual a conformação que vigorava até então é abalada em seu poder de interpretar o mundo cultural e anímico - será experienciada por cada um de forma singular, na relação com a cultura e instituições que se encarregam da juventude, dentre as quais se destaca a escola.

Vale lembrar, conforme Freud (1921/2011) propôs, que toda psicologia individual é também social, não havendo, assim, um purismo psíquico no qual o indivíduo engendraria seu próprio ser. É sempre no laço com o Outro que a constituição subjetiva se dá, isto é, são esses "pequenos outros" que encarnam o grande Outro que vão supor e atribuir sentido para as manifestações do bebê humano. Esse breve parêntesis serve para relançar a importância do laço social - que está no fundamento do inconsciente e do sujeito - de modo que possamos pensar os processos de subjetivação próprios à adolescência.

Esse corpo adolescente que se apresenta como estranho para o sujeito incita-o a buscar por novas significações, pois as anteriores se mostraram insuficientes para fazer frente ao enigma do sexo. Assim, o adolescente pode encontrar na cultura os termos que passarão a situá-lo no laço social. Ou seja, 
a ideia de um adolescente em crise veiculada na atualidade pode vir a ser um dos nomes a significar essa transição para um sujeito.

Corso e Corso (1999), colocando a tônica no que consideram os ganhos próprios à adolescência, firmam-na como momento de acontecimentos fundantes, marcado por um trabalho psíquico de elaboração da filiação, isto é, de questionamento da própria história que possibilitaria narrála e organizá-la pela primeira vez. Alberti (2009) destaca o fato de Freud afirmar que na puberdade há um desligamento da autoridade dos pais. Essa diferença de gerações carrega uma marca cultural e endossa a vertente anímica como sendo a preponderante na visada freudiana. Rassial (1999, p. 52), por seu lado, destaca que se trata de um momento lógico "em que a operação Nome-do-Pai [como Lacan nomeia esse significante da falta e ao mesmo tempo da lei] deve [...] sair de sua representação imaginária sustentada na família", ampliando e diversificando as referências simbólicas e as possibilidades de laço social.

Assim, vemos que a adolescência envolve uma elaboração da filiação no sentido de relativizar o lugar ocupado pelos pais em favor de uma pluralização de referenciais. Contudo, eis que nos deparamos com os modos com os quais o discurso social contemporâneo atribui sentidos à experiência adolescente que revelam obstáculos importantes a essa função simbolizante. Justamente, o que pretendemos destacar é que os adultos e suas instituições podem dificultar essa travessia do adolescente em busca de novas significações na medida em que se recusem em admitir a inexistência de uma satisfação plena a ser perdida ou reencontrada. Dois lados da mesma moeda: a adolescência ser caracterizada tanto como infortúnio quanto como ideal social.

Corso e Corso (1999) apontam que a adolescência suscita no adulto a irrupção de uma experiência traumática associada à idealização da infância própria à modernidade. É o momento no qual essa idealização é posta em xeque tanto por parte dos pais como por parte dos filhos, já que esses, mais do que nunca, não (co)respondem aos ideais imaginários desenhados nos sonhos parentais.

Paradoxalmente, para Pereira e Gurski (2014, p. 378), acompanhamos na contemporaneidade uma crescente centralidade do adolescente como "sujeito paradigmático do seu tempo social". Falam, portanto, nos termos de uma adolescência generalizada enquanto ponto de parada de um mundo em que predomina um excesso de presente e uma falta de perspectiva de futuro. A adolescência seria vista como o auge da perfeição, do gozo absoluto, da felicidade. Tornado depositário de um ideal social, o adolescente se vê confrontado com uma demanda excessivamente imaginarizada. Os adultos endereçam ao jovem uma demanda de "ser alguém" na chave de uma unidade imaginária sem furos. Assim, se de um lado tem-se a tônica na perda de uma infância idealizada, de outro lado, encontrase a demanda de que aquela criança sonhada pelos adultos como um adulto do futuro a quem nada falte (Lajonquière, 1999) venha, na adolescência, dar provas de que esse futuro chegou.

A resposta dada pelos adolescentes a esse imperativo de gozo é muitas vezes a da inadequação. Pereira e Gurski (2014) destacam não apenas a tendência à “tribalização”, mas uma série de patologias como toxicomania, déficit de atenção, transtornos, suicídio. Como chave de leitura destes fenômenos, os autores apontam para a tentativa de paralisar essa demanda em face da "impossibilidade de [...] ter alguma resposta sobre o dilema de ser algo desejável para alguém” (Pereira \& Gurski, 2014, p. 380). Mesmo quando não se trata de uma resposta patológica, há, em geral, uma sensação de desconforto nos adultos gerado pelo olhar crítico que os adolescentes muitas vezes dirigem a eles.

Projetar no adolescente o trauma da perda de uma infância idealizada ou a possibilidade de que essa perda não exista são duas formas de velar a impossibilidade estrutural de completude narcísica. Assim, a crise da adolescência mostra sua relação com algo que se passa no endereçamento da palavra dos adultos para com as crianças e adolescentes, ou seja, algo que diz respeito à educação que se dispensa às novas gerações. Com isso, nos perguntamos se a crise em questão não seria, portanto, aquela mesma que marca nossa época no que diz respeito à educação, na medida em que essa mobiliza o modo como se definem o passado e o futuro.

O endereçamento de uma palavra educativa ao adolescente carrega as marcas de uma relação do adulto com o passado. É essa própria relação que é experimentada de modo crítico a partir da modernidade e em especial com as transformações sociais aceleradas ao longo do século XX e início do XXI. Pode-se dizer que a modernidade se gesta, entre outras coisas, sobre a secularização da cultura e, portanto, sobre a abertura do futuro à indeterminação, desatrelando-o dos caprichos divinos. $O$ futuro passa a ser um tempo que precisa ser construído. Isso implica uma nova relação também com o passado. 
Lefort (1979/1999), tendo em vista a concepção humanista de educação gestada na Europa ainda no século XIV, fala de como a indeterminação quanto ao futuro, própria a uma nova relação com o saber ao se colocar em questão a providência divina, instaura uma nova relação com o passado. Esse não é mais visto como fonte de certezas quanto ao futuro, mas de todo modo fonte sobre a qual os homens devem se debruçar a fim de resgatar aquilo que faz falta no presente. Instala-se, com isso, a missão do presente de construir um futuro como uma obra baseada na leitura do passado enquanto restauração da identidade dos antigos.

Essa abertura do futuro à indeterminação, própria à modernidade, convocaria, segundo Lefort, a noção de responsabilidade, sobre a qual se debruça também Hannah Arendt (1957/2005) ao tratar da crise moderna na educação. Para Arendt, a noção de crise pode ser vista como a oportunidade, dado que desaparecem os preconceitos que serviam de apoio às decisões, de investigar a essência daquilo que está em crise. Em suas palavras:

Uma crise nos obriga a voltar às questões mesmas e exige respostas novas ou velhas, mas de qualquer modo julgamentos diretos. Uma crise só se torna um desastre quando respondemos a ela com juízos pré-formados, isto é, com preconceitos. Uma atitude dessas não apenas aguça a crise como nos priva da experiência da realidade e da oportunidade por ela proporcionada à reflexão (Arendt, 1957/2005, p. 223).

A indeterminação quanto ao futuro inaugurada com a modernidade põe em questão a essência da educação que, para Arendt (1957/2005, p. 223), reside no fato de que "seres nascem para o mundo". O educar no mundo moderno está permeado pela tensão entre a continuidade do mundo e a abertura para o novo. A crise educacional revela a crise própria ao mundo moderno e, ao mesmo tempo, dá a oportunidade de refletir sobre aquilo que é essencial, ou seja, sobre o que a chegada das crianças ao mundo humano impõe àqueles que já estão aí. Quanto a isso, Arendt sustenta que a chegada dos novos exige dos adultos que se responsabilizem tanto por esse novo ser ainda em formação quanto pelo mundo, por sua preservação face à chegada do novo que pode lhe ser destrutivo. Distinguindo aquilo que diz respeito à preservação da vida e à preservação do mundo, coloca a dupla tarefa da educação: proteger a vida da criança face aos perigos do mundo e proteger o mundo dos perigos que a chegada de um novo ser coloca à sua continuidade.

Quanto a esse segundo aspecto, destaca a filósofa que o educador, em face da criança, é aquele que assume a função de ser "representante de um mundo pelo qual deve assumir a responsabilidade, embora não o tenha feito e ainda que secreta ou abertamente possa querer que ele fosse diferente do que é" (Arendt, 2005, p. 239). É isso, inclusive, que lhe pode conferir autoridade: assumir, diante daqueles que acabam de chegar, a responsabilidade pela conservação do mundo.

Contudo, o estranhamento do mundo próprio à modernidade, radicalizado "sob as condições de uma sociedade de massa" (Arendt, 2005, p. 242), enseja o que autora chama de "pathos do novo", dando margem a uma recusa da responsabilidade em favor de uma educação vista como instrumento político de construção de um mundo novo em detrimento do velho, como se fosse simplesmente possível a ruptura da continuidade em que as mudanças nesse nosso único velho mundo têm lugar.

Arendt atribui à perda moderna da autoridade um duplo sentido: tanto significa a exigência de uma responsabilidade compartilhada quanto um repúdio de toda responsabilidade. Contudo, no que tange à educação, mesmo o primeiro dos sentidos da perda de autoridade, ou seja, sua substituição por uma responsabilidade comum, reinstala a própria autoridade geracional naquilo que ela tem de distinto da autoridade política que é o fato de se sustentar numa assimetria temporal e temporária. Tornar objetivo da educação a construção de um mundo novo é uma ilusão, pois justamente aí se priva à nova geração "sua própria oportunidade face ao novo" (Arendt, 1957/2005, p. 226).

Para a autora, esse "pathos do novo" teve como uma de suas consequências no campo da educação a suspensão do "juízo humano normal” (Arendt, 1957/2005, p. 227) em favor de teorias educacionais. Podemos, a partir de outros referenciais, destacar a emergência no campo educacional de um discurso pedagógico normativo calcado na ciência positiva por onde a indeterminação quanto ao futuro dá lugar às certezas de poder controlar os meios e fins da educação visando a consecução de um ideal de progresso. 
Tudo isso compete para a perda da noção de responsabilidade. É o que Arendt denuncia quando fala de um aprofundamento da crise na educação dada a rejeição por parte dos adultos da responsabilidade pela preservação do mundo comum - recusa dos adultos "a assumir a responsabilidade pelo mundo ao qual trouxeram as crianças" (Arendt, 2005, p.240). Nesse sentido, o "pathos do novo" apontaria para uma ruptura com a tradição em favor de referenciais tecnocientíficos que, paradoxalmente, reinstalariam uma forma de relação com o futuro no qual a indeterminação estaria ameaçada.

Walter Benjamim (1933/1987), nas primeiras décadas do século XX, aponta o que considera a miséria própria à modernidade decorrente, justamente, do progresso técnico que abala a ligação com o passado. O futuro desvinculado do passado passa a ser um futuro não mais indeterminado porque não mais tensionado pelo resgate do "teria sido". Os restos do passado, aquilo que lhe falta, são entregues ao saber tecnocientífico, transformado em certezas e impedindo as indagações.

O progresso técnico como fim em si mesmo passa a operar como nova forma de justificacionismo onde antes encontrávamos a religião. No campo educacional, vê-se a conformação de um discurso pedagógico normativo que acompanha, ao longo do século XIX, a conjugação da ciência positiva com o nascimento do poder médico-pedagógico. $\mathrm{O}$ futuro passa a ser depositado no saber emergente da experimentação, que funciona como um saber normativo a partir do que supõe ser o desenvolvimento natural das potencialidades psicológicas da criança (Lajonquière, 1999).

O discurso médico-pedagógico positivista e normativo que se consolida ao longo do século XX no âmbito tanto das instituições escolares como de tratamento de crianças e adolescentes com transtornos psíquicos é objeto de reflexão de Maud Mannoni (1977). A psicanalista se debruça sobre o efeito de captura que esse discurso opera na palavra pessoal dos adolescentes. Ela está às voltas em pensar a escolarização dos que foram excluídos da escola normal na França do século passado, quando afirma que a pedagogia subordina a educação à imagem de um ideal que não pode ser questionado, pedindo que o aluno venha "ilustrar o bom fundamento de uma doutrina" (1977, p.50). Daí emerge aquilo que denuncia como educação impossível.

A autora, em seu clássico livro sobre o tema, retoma o aforismo freudiano sobre as três profissões impossíveis para pontuar uma distinção do que ela destaca como sendo da ordem de uma redução das chances da educação vir a ter efeitos subjetivantes. É precisamente essa diferença entre a impossibilidade inerente ao educar - a qual tem relação precisamente com o caráter indeterminado de seus efeitos - e uma educação impossibilitada de ter efeitos de sujeito - na medida em que pretende controlar os resultados educativos por meio de métodos e técnicas - que coloca os maiores desafios às instituições educativas voltadas aos adolescentes.

Assim, o excesso de presente e o futuro entregue à mera repetição do mesmo marcam a experiência subjetiva na contemporaneidade e dificultam a travessia adolescente. A lógica da eficiência e do rendimento é denunciada por Mannoni (1977) como aquela que faz com que as instituições atuem no sentido de serem um fim em si mesmo, não oferecendo qualquer perspectiva de futuro. Enquanto os jovens estariam em busca de uma "razão de viver", entre os adultos imperaria uma ausência de sonhos de superação ou, quando esses aparecem, são desvinculados da prática cotidiana.

Como efeito desse processo, temos o adensamento de uma discussão nosográfica pautada pela patologia como nome dado ao que comparece como mal-estar no laço estabelecido com o adolescente na contemporaneidade. Pais e filhos se debatem em seus processos doloridos de desidealização de uma infância investida narcisicamente enquanto encontram na cultura sentidos que pretendem eternizar a adolescência como tempo estático do imperativo de felicidade. A palavra crise vem, portanto, nos convocar ao exercício arendtiano de revisitar nossas referências na formulação de respostas - sejam elas novas ou velhas - pelas quais não só assumimos responsabilidade como também nos implicamos em buscar balizas para a construção de um futuro que, contudo, reitere a abertura significante necessária ao advento do novo.

Daí a importância que ganha a instituição escolar no que entendemos ser sua função primordial, um lugar heterogêneo ao familiar que tem a função de apresentar o mundo e transmitir aquilo que as sociedades entenderam ter uma importância que transcende o tempo de uma vida humana ao ser passado de geração em geração. A escola é lócus no qual o jovem vai encontrar outros pares que poderão acompanhá-lo nesse momento de travessia. 


\section{JOVENS E EXPERIÊNCIA ESCOLAR}

Nesse cenário educativo, como pensar a experiência escolar dos jovens? Sendo a adolescência um tempo de transformação marcado pela abertura a novas significações e pela ampliação do laço social, é importante pensar como a escola tem conseguido acolher esses jovens sem operar o "rapto do sujeito", para usar uma noção de Mannoni (1977).

Deslocando a questão da crise da adolescência de um âmbito individual e como simples consequência de uma fase da vida determinada por mudanças orgânicas, apontamos sua estreita relação com o modo como a adolescência tem efeitos no laço social e sua crise desvela algo que diz respeito ao educar no mundo moderno. Também destacamos como as respostas a essa crise engendram, no lugar dos desígnios divinos, uma nova forma de justificacionismo calcado no tecnocientificismo herdeiro da ciência positiva e aliado à ideia evolucionista de progresso.

Ainda assim, sustentamos a ideia de que a instituição escolar pode vir a desempenhar um importante papel simbolizante para a experiência subjetiva dos adolescentes em sua travessia para a vida adulta. Porém, resta indagar de que forma a escola pode fazer frente a esse discurso social hegemônico em que impera a recusa dos adultos de sua responsabilidade por um mundo marcado pela falta de uma satisfação plena a ser perdida e/ou reencontrada.

Rosa e Carmo-Huerta (2020) apontam que o despertar adolescente não pode ser pensado desenraizado da cena política na qual ele se dá. É necessário haver um amparo simbólico mínimo na lógica discursiva, social e política ao sujeito adolescente. Nesse sentido, as autoras colocam o foco nos corpos marginalizados que têm suas manifestações desqualificadas em nossa cultura, frequentemente sendo tomadas como signo de criminalidade - a forma de vestir, o linguajar próprio aos grupos ou até mesmo o gosto musical. Elas apontam que cabe ao discurso social permitir que o adolescente venha a "afirmar-se em um laço discursivo em que possa, ao contar sua própria história, também narrar a história de seu tempo, a contrapelo da história oficial, iluminando o escuro dos laços em jogo" (Rosa e CarmoHuerta, 2020, p. 17).

A desqualificação e subordinação dos corpos também adentram a instituição educativa fazendo com que a escola não se constitua como território de deslizamentos significantes, antes o contrário, ela sela destinos, rotula e estigmatiza.

Silvia Duschatzky (2008, p.5, tradução nossa), docente da FLACSO e que dedica suas pesquisas a pensar a experiência escolar de jovens de camadas populares, define a escola como sendo um lugar de fronteira:

A escola, para o Jovem de nosso universo, constitui uma possibilidade, um encontro incompleto que mais do que fechar o campo experiencial, define umbrais para novos encontros. Pensar a escola em termos de possibilidade e não de discurso auto-suficiente e excludente nos livra da ilusão pedagógica de convertê-la em lugar "total” de constituição da identidade juvenil.

Para a autora, a escola deveria manter a abertura da cadeia de significantes mais do que buscar encerrar o jovem em mais uma significação que lhe seja imposta. $O$ vazio de significação, aberto pela insuficiência das identificações infantis, acaba sendo preenchido com os signos do fracasso escolar, da evasão, do tecno-cientificismo utilitarista da profissionalização, com uma vida no crime, o elogio ao suicídio... São muitas as suas figuras na atualidade.

O que nos parece central é afirmar que, dentro deste cenário de transição que marca a adolescência, a errância em busca de novas significações subjetivas pode encontrar no território escolar um espaço para ser experimentada sem que, apressadamente, seja capturada em um sentido fechado e frequentemente excludente.

Voltolini (2019) destaca o processo pelo qual a instituição escolar vem perdendo terreno para a noção de organização. Enquanto "a preocupação primeira de toda organização é seu funcionamento, seu vigor e sua perpetuação", a preocupação da "instituição é a de promover aquilo que a erigiu como tal, que a fundou com uma função específica” (Voltolini, 2019, p.381). Esse debate permite 
que retomemos uma colocação de Mannoni (1977, p. 189) quando afirma que "Toda instituição separada de um interesse que a suplanta possui efeitos mortíferos".

A escola tem por função acolher os adolescentes de modo que eles possam ter acesso ao conhecimento acumulado através das gerações que o precederam e com isso criar sentidos e narrativas possíveis que inscrevam sua experiência no laço social. Se, atualmente, vivemos um tempo no qual a lógica da organização suplanta a da instituição, devemos estar atentos para a advertência que faz Voltolini (2019, p.381) quando se interroga acerca das consequências desse declínio uma vez que para a psicanálise "a institucionalidade é um elemento que joga um papel fundamental na organização civilizatória".

Trata-se de insistir na função simbolizante que a escola pode exercer na experiência desses jovens quando a separação das figuras parentais dá novo impulso à abertura de significações. Rassial (1999, pp. 48-9) ressalta que essa separação das figuras parentais é acompanhada da "constatação de que os pais não são fundadores, mas transmissores, já que eles mesmos tiveram pais, avós, que puderam indicar um impossível Outro do Outro". O autor faz referência, com essa expressão, a uma formulação lacaniana que diz respeito precisamente a essa inexistência de um significante capaz de completar a cadeia da significação. Em outras palavras, se trata da mesma afirmação da inexistência de um pai todopoderoso capaz de dar a última palavra acerca do devir do mundo humano. A inexistência desse Outro absoluto é precisamente o que sustenta a importância de que os adultos se responsabilizem pelo mundo e pela introdução, nesse mundo, das crianças.

Essa queda da força do institucional em prol de sistemas organizativos no campo escolar faz com que desloquemos o debate para por em causa a escola que tem se desenhado para um futuro próximo. Nesse sentido, as experiências de jovens - em especial os de classe populares, mas não só devem ser analisadas como forma de conhecer os efeitos sobre a subjetividade de um discurso tecnicista e utilitarista que vem ganhando terreno e se multiplicando no furor avaliativo (Passone, 2015) que mede mecanismos de adaptação sustentados na falaciosa qualidade escolar em detrimento da transmissão de um legado simbólico e de pertencimento ao mundo.

A escola padece da crise do mundo moderno, tanto de voltar atrás quanto de ir simplesmente em frente. Arendt fala que o estranhamento do mundo tomou a forma de um processo automático. Contudo, alerta que resta "não esquecermos que está ao alcance do poder do pensamento e da ação humana interromper e deter tais processos" (Arendt, 1957/2005, p. 245). Isso implica precisamente um passo ético. É nesse contexto que se pode vislumbrar a contribuição que a visada ética da psicanálise em seu encontro com o campo educativo traz no que tange ao desafio da escola contemporânea naquilo que oferta aos adolescentes.

\section{EDUCAR E PSICANALISAR: UM PASSO ÉTICO}

Nas palavras de Gurski (2017, p.222), a ética da psicanálise pretende possibilitar ao sujeito "resistir à tirania do UM e viabilizar modos dele não se curvar a nenhuma totalidade do Outro". Voltolini (2011), também sustentando a mesma posição ética no campo da psicanálise e educação, precisa que a psicanálise não entra em campo para responder ou elucidar os problemas educativos, mas para causar questões nas quais os sujeitos possam se implicar.

A ideia freudiana da impossibilidade própria ao ato de educar aponta para uma posição ética em face do desafio da modernidade no que diz respeito à tradição. A dimensão do impossível introduzida por Freud (1937/2018) aponta para a necessidade de preservar vazio o lugar deixado vago pela destituição moderna da figura de um pai todo-poderoso ao invés de alimentar novas formas de justificacionismo que, na educação, tomam a forma de uma natureza infantil a ser preservada ou reencontrada por meio de métodos e técnicas condizentes com o tecnocientificismo.

Segundo Lajonquière (2010), o desafio próprio à modernidade é o de reconhecer a ilusão tanto de um pai todo-poderoso que, tendo sido assassinado, precisaria ser reposto, quanto de uma natureza infantil que, tendo sido perdida, necessitaria ser reencontrada. Tal reconhecimento exige um trabalho ético incessante de reinvenção da política sustentada numa responsabilidade compartilhada. Assim, o endereçamento da palavra educativa se dá a partir do reconhecimento de uma dívida simbólica impagável com o passado, mas que pode ser passada à futura geração.

É somente com essa reinvenção da política no mundo dos velhos que se pode enfrentar o desafio de receber nesse mundo os novos, dando testemunho de nossa responsabilidade em passar 
adiante essa dívida que é a da nossa própria fragilidade de origem. $\mathrm{O}$ adolescente, por estar nesse entremeio entre o ser pequeno e o ser grande, nos coloca de modo mais agudo diante dessa condição crítica de se tornar velho no mundo moderno. Ainda mais face à exacerbação das forças totalizantes que não poupam esforços em rechaçar o desejo como sopro do pouco de humanidade que nos resta.

Debruçar-se sobre a ideia de crise da adolescência nos permite pôr em pauta a escola que temos oferecido aos nossos jovens. Que destinos têm sido traçados nessa instituição? Quais as formas que temos encontrado para acolher as manifestações singulares e idiossincráticas? Que o adolescente possa dizer de si e que sua palavra pessoal venha atualizar o que foi dito sobre ele em uma dinâmica discursiva: essa é uma forma de anunciar a visada ética da psicanálise no campo educativo no que concerne aos jovens na contemporaneidade.

\section{REFERÊNCIAS}

Alberti, Sonia (2009). Esse sujeito adolescente. Rio de Janeiro. RJ: Rios Ambiciosos/Contra Capa.

Amaral, Monica G. T. (1995). Os três ensaios sobre a teoria da sexualidade: um texto perdido em sucessivas edições? Psicologia USP, 6 (2), 63-84. Doi:10.1590/S1678-51771995000200004.

Anacleto, Julia M. B. (2019). Conhecimento e desejo de saber: de Piaget a Lacan. São Paulo, SP: Instituto Langage.

Arendt. Hannah (2005). Entre o passado e o futuro. São Paulo, SP: Perspectiva. (Trabalho original publicado em 1957).

Benjamin, Walter (1987). Experiência e pobreza. In W. Benjamin, Obras escolbidas. Magia e técnica, arte e politica (Vol. 1, pp. 114-119). São Paulo, SP: Brasiliense. (Trabalho original publicado em 1933).

Corso, Mario \& Corso, Diana (1999). Game over. In Associação Psicanalítica de Porto Alegre (Org.). Adolescência entre o passado e o futuro. Porto Alegre, RS: Artes e Ofícios.

Duschatzky, Silvia (2008). La escuela como frontera: reflexiones sobre la experiencia escolar de jovenes de sectores populares. Buenos Aires, Argentina: Paidós.

Freud, Sigmund (1996) Três ensaios sobre a teoria da sexualidade. In S. Freud, Edição standard brasileira das obras psicológicas completas de Sigmund Frend: um caso de histeria, três ensaios sobre sexualidade e outros trabalhos (1901-1905) (Vol.7, pp. 119-234). Rio de Janeiro, RJ: Imago. (Trabalho original publicado em 1905).

Freud, Sigmund (2011). Psicologia das massas e análise do eu In: S. Freud, Obras completas: Psicologia das massas e análise do eu e outros textos (1920-1923) (Vol. 15, pp. 13-113). São Paulo, SP: Companhia das Letras. (Trabalho original publicado em 1921).

Freud, Sigmund (2018). A análise finita e a infinita. In S. Freud, Obras incompletas de Sigmund Freud: fundamentos da clínica psicanalitica (pp. 315-364). Belo Horizonte, MG: Autêntica. (Trabalho original publicado em 1937).

Gurski, Roselene (2017). Os novos sintomas na educação de adolescentes de hoje: notas sobre o Saber Fazer com "isso". In M. R. Pereira (Org). Os sintomas na educação de hoje: o que fazemos com "isso"?. Belo Horizonte, MG: Scriptum.

Lacan, Jacques (1995). O seminário, livro 4: a relação de objeto, 1956-57. Rio de Janeiro, RJ: Jorge Zahar. (Apresentação oral em 1956-57, publicação original em 1994). 
Lacan, Jacques (1998). Subversão do sujeito e dialética do desejo no inconsciente freudiano. In J. Lacan, Escritos (pp. 807-842). Rio de Janeiro, RJ: Jorge Zahar. (Trabalho original publicado em 1960).

Lacan, Jacques (1999). O seminário, livro 5: as formações do inconsciente, 1957-58. Rio de Janeiro, RJ: Jorge Zahar. (Apresentação oral em 1957-58, publicação original em 1998).

Lajonquière, Leandro (1999). Infância e ilusão (psico)pedagógica: escritos de psicanálise e educação. Petrópolis, RJ: Vozes.

Lajonquière, Leandro (2010). Figuras do infantil: a psicanálise na vida cotidiana com as crianças. Petrópolis, RJ: Vozes.

Lefort, Claude (1999). Formação e autoridade: a educação humanista. In C. Lefort, Desafios da escrita política. São Paulo, SP: Discurso Editorial. (Trabalho original publicado em 1979).

Mannoni, Maud (1977). Educação impossivel. Rio de Janeiro, RJ: Francisco Alves.

Mateus, Tiago C. (2007). Adolescência: história e politica do conceito na psicanálise. São Paulo, SP: Casa do Psicólogo.

Passone, Eric (2015). Produção do fracasso escolar e o furor avaliativo: o sujeito resiste? Estilos Da Clínica, 20(3), 400-421. Doi: 10.11606/issn.1981-1624.v20i3p400-420.

Pereira, Marcelo R. \& Gurski, Roselene (2014) A adolescência generalizada como efeito do discurso do capitalista e da adultez erodida. Psicologia \& Sociedade, 26(2), 376-383. Doi: 10.1590/S010271822014000200014 .

Rassial, Jean Jacques (1999). A adolescência como conceito da teoria psicanalítica. In Associação Psicanalítica de Porto Alegre (Org.). Adolescência entre o passado e o futuro. Porto Alegre, RS: Artes e Ofícios.

Rosa, Miriam D. \& Carmo-Huerta, Viviani (2020). O que resta da adolescência. Estilos Da Clínica, 25(1), 5-20. Doi: 10.11606/issn.1981-1624.v25i1p5-20

Safouan, Mustafa (1970). Estruturalismo e psicanálise. São Paulo,SP: Cultrix.

Voltolini, Rinaldo (2011). Educação e Psicanálise. Rio de Janeiro, RJ: Zahar.

Voltolini, Rinaldo (2019). A insustentável leveza da escola. Estilos Da Clínica, 24(3), 380-383. Doi: 10.11606/issn.1981-1624.v24i3p380-383.

Submetido: $16 / 07 / 2020$

Aprovado: $14 / 12 / 2020$ 